\title{
Optimism and adaptation to chronic disease: The role of optimism in relation to self-care options of type I diabetes mellitus, rheumatoid arthritis and multiple sclerosis
}

\author{
Marijda Fournier*, Denise de Ridder and Jozien Bensing \\ Department of Health Psychology, Utrecht University, The Netherlands
}

\begin{abstract}
Objectives. To determine the role of optimistic beliefs in adaptation processes of three chronic diseases different in controllability by self-care. It was expected that optimism towards the future would relate to adaptation independently of the controllability of disease. Optimism regarding one's coping ability should be beneficial in controllable diseases. Unrealistic optimism was expected to be beneficial in uncontrollable disease.
\end{abstract}

Design. The cross-sectional design involved 104 patients with type I diabetes, 95 patients with rheumatoid arthritis and 98 patients with multiple sclerosis, recruited via their physician at the out-patient department of five hospitals.

Method. Confirmatory Factor Analysis (LISREL) was employed to confirm a threedimensional approach of optimism: outcome expectancies, efficacy expectancies and unrealistic thinking. Multi-sample analysis by path modelling was used to examine whether the relationship of the three optimistic beliefs with coping (CISS-2I), depression and anxiety (HADS), and physical functioning (SF-36) differs with the controllability based on the self-care options of chronic disease.

Results. These show that when chronic disease must be controlled by self-care, physical health depends more strongly on positive efficacy expectancies. In contrast, when self-care options for controlling chronic disease are limited, physical health depends more strongly on positive unrealistic thinking and relates negatively to positive efficacy expectancies. The impact of the three optimistic beliefs on mental health is independent of the controllability by self-care.

Conclusion. Optimistic beliefs are differently beneficial for physical health dependent on the controllability of chronic disease. Unrealistic beliefs are helpful when patients are confronted with moderately to largely uncontrollable disease where self-care options are limited, in contrast to positive efficacy expectancies that are helpful when patients deal with largely controllable disease where self-care is required.

*Requests for reprints should be addressed to Marijda Fournier, Department of Health Psychology, Utrecht University, PO Box 80.I40, 3508 TC Utrecht, The Netherlands (e-mail: gpsecr@fss.uu.nl). 
A growing number of studies has demonstrated that optimism, conceptualized as a coping resource (Lazarus \& Folkman, 1984), plays a significant role in adaptation to chronic disease. Generally, optimistic patients with rheumatoid arthritis (Brenner, Melamed, \& Panush, 1994), multiple sclerosis (Barnwell \& Kavanagh, 1997), Parkinson's disease (Shifren, 1996), breast cancer (Carver et al., 1993), or HIV infection (Taylor, Kemeny, Reed, \& Aspinwall, 1991) report better psychosocial and physical functioning. Although it has been shown that more optimistic patients' active coping style and mental engagement are factors contributing to better functioning (Carver et al., 1993; Taylor, Kemeny, Reed, \& Aspinwall, 1991), the question of how optimism affects adaptation to chronic disease is still a matter of debate. In the present study, the role of optimism in adaptation to chronic disease is examined in relation to disease controllability by self-care.

Although the meaning of optimism seems quite obvious, there is some variation in its definition in the literature. As a consequence, it remains unclear what the concept of optimism entails and whether different conceptions have a similar role in adapting to chronic disease. A number of specific distinctions of different types of optimism have been made in the literature, such as functional versus defensive optimism (Schwarzer, 1994), positive outcome expectancies versus efficacy expectancies (Bandura, 1988; Carver \& Scheier, 1994), and cautious optimism (realistic) versus 'cockeyed' optimism (unrealistic) (Wallston, 1994). Research has shown that three major optimistic beliefs can be distinguished; namely, positive outcome expectancies, positive efficacy expectancies, and positive unrealistic thinking (Fournier, de Ridder, \& Bensing, 1999; Schwarzer, 1999).

Positive outcome expectancies are reflected in the belief that one will generally experience good outcomes in life (Scheier \& Carver, 1985). Positive efficacy expectancies are reflected in the belief that the individual will be able to cope in a wide range of demanding situations (Schwarzer, 1994). Positive unrealistic thinking is reflected in the belief that pleasant events are more likely to happen to the self than to others, and in the belief that negative events are less likely (Taylor, 1989; Weinstein, 1980).

These three optimistic beliefs relate to different functions in the adaptive process. Positive outcome expectancies are a key component in the theory of behavioural selfregulation (Carver \& Scheier, 1998), which explains the degree of engagement in obtaining desired (or alternative) outcomes. Patients with positive outcome expectancies display engagement in dealing with their health, even when they are confronted with adversity. Positive efficacy expectancies are a key component in social cognitive theory (Bandura, 1988), which explains competent and skilled behaviour. Patients with positive efficacy expectancies will handle their disease more competently. Positive unrealistic thinking is a key component in the theory of cognitive adaptation (Taylor, 1989). It explains how patients are buffered against the assimilation of negative information into their expectancies and beliefs. Positive unrealistic thinking helps patients to accentuate positive elements of their health and play down the negative ones. This attitude helps patients to prevent hopelessness and depression. Nevertheless, Weinstein (1980) argues that due to positive unrealistic thinking patients may fail to practice appropriate health behaviours, which may increase the threat of negative consequences for their health.

Based on these theoretical differences in the role of optimism in behavioural adaptive processes, we hypothesize that the function of optimism in adaptation to chronic disease depends on the self-care options in the management of chronic illness. More particularly, we expect positive efficacy expectancies to be particularly adaptive in 
chronic diseases that require skilled self-care behaviour for their management. Positive unrealistic thinking, in contrast, will be adaptive in uncontrollable chronic diseases where patients have few options to influence the disease course by their behaviour and have to deal with a negative uncontrollable situation. However, positive unrealistic thinking will be maladaptive when skilled self-care behaviour is required for controlling disease. Finally, we expect that positive outcome expectancies will be adaptive in any kind of disease independent of its controllability by means of self-management.

In order to investigate these hypotheses, patients with three chronic diseases differing in controllability by self-care were studied. By examining optimism in a controllable, a partly controllable and a largely uncontrollable chronic disease, it is possible to determine whether the function of optimism depends on the controllability of chronic disease. Controllability has been defined as the actual or perceived ability to determine outcomes of an event (Eitel, Hatchett, Friend, Griffin, \& Wadhwa, 1995). In the present study, actual controllability is determined by the self-care options available to influence health status or course of the illness. This is based on the medical knowledge on disease course and on the requirements and possibilities for patients to self-regulate their disease. Perceived controllability is determined by the extent to which patients perceive that their disease is controllable by means of self-care behaviours (Eitel et al., 1995). As several studies demonstrate that perceived controllability, as measured by an adapted version of the Multidimensional Health Locus of Control scale (MHLC), is sensitive for situational differences and has been shown to become more external for rheumatoid arthritis patients and more internal for diabetic patients (Felton, Revenson, \& Hinrichsen, 1984; Halfens \& Philipsen, 1988), the MHLC appears to be useful for determining perceived disease controllability.

Disease controllability defined as options for medical self-care is highly relevant for explaining differences across chronic diseases, as previous studies demonstrate that differences could not be attributed to the specific diagnosis or to psychosocial processes, which are largely similar for various diseases, but could be explained by the differential role of medical self-care (Cassileth et al., 1984; Felton et al., 1984; Penninx et al., 1996; Pollock, 1993).

A chronic disease that is largely controllable by self-care is type 1 diabetes mellitus (IDDM), which is characterized by a dysfunctional metabolism system with fatal consequences if untreated. To survive, patients have to monitor and adjust their blood glucose level by means of daily insulin injections, dietary modification, exercise therapy and self-administered blood tests (Cox, Gonder-Frederick, \& Saunders, 1991). IDDM typically begins before the age of 30 and the onset is most likely between ages 5 and 12. IDDM occurs equally often in men as in women (Cox et al., 1991).

A chronic disease that is partly controllable by self-care is rheumatoid arthritis (RA), which is characterized by a progressive and unpredictable course, with intermittent periods of disease flare and remission. By adapting rest, exercise and medication to the changing disease activity, patients can partly alleviate their pain, the extent of joint destruction and their physical functioning (Lorig et al., 1989). RA mostly becomes manifest between the ages of 20 and 50. Women are more affected than men, with an overall ratio of 2 to 1 (Miedema, van der Linden, Rasker, \& Valkenburg, 1998). In contrast to IDDM patients, self-care is less compelling and less effective for RA patients.

Multiple sclerosis (MS) is a largely uncontrollable disease, as self-care options are limited, and is characterized by an unpredictable and variable course with varying types of neurological symptoms, fatigue, cognitive deficits, and pain (Paty \& Poser, 1984). The lack of any cure or treatment, and the unpredictability of exacerbation and remission 
means that MS patients have to adapt to the uncontrollability and to accept the consequences of increasing disability for social and vocational life (Antonak \& Livneh, 1995). MS patients have a few options through which they can regulate their disease, for example, stress management and exercise (Stuifbergen, 1995). However, these self-care options only have a limited influence on disease-related factors and quality of life (Stuifbergen, 1995). MS mostly occurs between the ages of 20 and 50 with a peak incidence around 30 years of age. Women are more affected than men, with an overall ratio of 2 or 3 to 1 (Zwanikken, 1997).

Given the differences in controllability by self-care implications of these three diseases, we investigated whether optimistic beliefs differentially relate to coping and adaptation by means of path modelling. Based on the coping theory of Lazarus and Folkman (1984), optimistic beliefs are characterized as person-related coping resources that determine their success in behaviourally and emotionally coping with distressing problems and emotions caused by disease. Optimistic beliefs are also found to directly relate to adaptation in medically ill patients (e.g. Brenner et al., 1994; Epping-Jordan et al., 1999). Therefore, optimistic beliefs are assumed to directly and indirectly relate to less anxiety, depression and better physical functioning in chronic disease.

More particularly, we expected that positive efficacy expectancies would relate (directly and indirectly) to less anxiety, depression and better physical functioning in IDDM because IDDM needs to be managed by skilled self-care behaviours. Positive efficacy expectancies were expected to be intermediately adaptive in RA because RA benefits partly from skilled self-care behaviour. In MS, positive efficacy expectancies were expected to play a neutral role because the symptoms are beyond the patient's control. In contrast, positive unrealistic thinking should be related (directly and indirectly), to less anxiety, depression and better physical functioning in MS, because the uncontrollability of MS and its major relapses require accentuation of positive elements to ensure well-being. It was expected to play a neutral role in RA because both a realistic view, for managing the symptoms, and an unrealistic view, in order to accept the uncontrollable disease flares, are both necessary. Finally, positive unrealistic thinking was expected to relate to more anxiety, depression and worse physical functioning in IDDM, because a realistic view of what needs to be done is required to manage IDDM effectively. Positive outcome expectancies were expected to be similarly adaptive in all three diseases.

\section{Method}

\section{Procedure}

Patients were approached via their physicians at the out-patient departments of five hospitals in the Netherlands. They were eligible for inclusion in the study if they met the following criteria: (1) diagnosis according to the criteria for classification (type 1 diabetes: Expert Committee on the Diagnosis and Classification of Diabetes Mellitus (ECDCD), 1997) (MS: Poser et al., 1983) (RA: American College of Rheumatology (ACR), 1987 criteria; Arnett et al., 1988); (2) age between 18 and 65 years at the time of the interview; (3) diagnosed at least 1 year prior to the study. Patients were excluded where they met the following criteria: (1) severe disability due to disease (IDDM: retinopathy, neuropathy, renal disease and macrovascular disease; RA: class IV functional status of the ACR-1991 (Hochberg et al., 1992); MS: Expanded Disability Status Scale (EDSS) 7.0 and higher); (2) significant comorbidity (such as asthma, heart disease, cancer); (3) 
receiving psychotherapy, psychosocial counselling or using psychotropic medication at the time of research.

Inclusion and exclusion criteria were chosen in order to make the phase of adaptation for the three diseases as comparable as possible. Patients in their first year of diagnosis were excluded because, during that year, patients are confronted with different adaptive tasks: IDDM patients experience the 'honeymoon' period with temporary recuperation of the metabolism system (Heinze \& Thon, 1983), RA patients grapple with the severe physical effects (Shaul, 1995), while MS patients generally experience temporary relief followed by an emotional collapse (Antonak \& Livneh, 1995). One year post-diagnosis, patients are aware of the irreversibility of their disease and they realize that they have to continue their life regardless of the changes in their circumstances. Our data substantiated that the IDDM, RAand MS patients experienced a comparable phase of adaptation, as $80 \%$ of the IDDMand RApatients, and $84 \%$ of the MS patients indicated that, even though they realized that they had a chronic disease, their feeling was that their life was continuing (integration phase). This information was gathered by asking patients to choose between five statements each indicating a different adaptation phase (denial, resistance, grief, acceptance, integration) (Zwanikken, 1997).

\section{Participants}

The physicians distributed a leaflet on the study among 155 IDDM patients, 155 MS patients and 158 RA patients. A total of 297 patients agreed to participate in the study and gave their informed consent: 104 IDDM patients (45 male and 59 female), 95 RA patients (32 male and 63 female), and 98 MS patients (39 male and 59 female) (see Table 1). Assessment took place at the hospital and included a number of questionnaires. Although the male-female proportions were comparable in the three samples, sex differences in optimism were found in the IDDMsample group, but not in the MS or RA sample groups. Male IDDM patients had significantly more positive efficacy expectancies $(M(\mathrm{~m})=31.6 ; M(\mathrm{f})=30.0 ; p<.05)$, and reported more positive unrealistic thinking than female IDDM patients $(M(\mathrm{~m})=80.3 ; M(\mathrm{f})=74.5 ; p<.05)$.

Mean ages were significantly different among the samples, IDDM patients being younger than MS patients, who were in turn younger than RApatients (see Table 1). This is related to the incidence of IDDM at an earlier age than RA or MS. All patients were younger than 65, and thus had been confronted with their disease during working life. Some differences were assessed in social variables, related to age-and cohort effects. Fewer IDDM patients had children, compared with RA patients and MS patients. More IDDM patients had a job compared with RA and MS patients. Reasons for not working were primarily inability to work, housekeeping, early retirement or daily schooling.

As a result of the characteristic variation in disease activity in RA and MS, $20 \%$ of RA and MS patients reported aggravation or improvement of their symptoms during the month prior to the research, in contrast to only $4 \%$ of IDDM patients. In greater detail, we observed that $38 \%$ of the 104 IDDM patients did not report symptoms at the time of research, while $31 \%$ reported an unstable blood sugar level, $26 \%$ reported fatigue, and $8-12 \%$ reported the first symptoms of complications (impaired vision or decreased sensitivity in hands/feet). Of the 95 RA patients, $72 \%$ experienced stiff joints, $65 \%$ reported pain, $54 \%$ experienced fatigue, and $53 \%$ reported difficulty in walking. Most patients used disease-modifying anti-rheumatic drugs (DMARDs) (91\%), and nonsteroidal anti-inflammatory drugs (NSAIDs) (70\%), while $12 \%$ used prednisone/ 
Table I. Demographic information for the IDDM, RA and MS sample groups

\begin{tabular}{|c|c|c|c|c|}
\hline & $\begin{array}{c}\text { IDDM } \\
N=104\end{array}$ & $\begin{array}{c}\text { RA } \\
N=95\end{array}$ & $\begin{array}{c}M S \\
N=98\end{array}$ & $\begin{array}{c}p \\
(\text { ANOVA) }\end{array}$ \\
\hline \multicolumn{5}{|l|}{ Gender } \\
\hline Male versus female & $45: 59$ & $32: 63$ & $39: 59$ & .38 \\
\hline \multicolumn{5}{|l|}{ Age } \\
\hline Mean (SD) & $33(9.6)^{\mathrm{a}}$ & $52(9.4)^{b}$ & $45(9.3)^{b, c}$ & $<.001$ \\
\hline Range & $18-64$ & $30-65$ & $20-63$ & \\
\hline \multicolumn{5}{|l|}{ Time since diagnosis } \\
\hline Mean (SD) & II $(4.5)^{\mathrm{a}}$ & $6(4.2)^{b}$ & $4(3.4)^{b, c}$ & $<.001$ \\
\hline Range & $1-17$ & $1-17$ & $1-17$ & \\
\hline \multicolumn{5}{|l|}{ Marital status } \\
\hline Partner & $75 \%$ & $83 \%$ & $82 \%$ & .29 \\
\hline Children & $47 \%^{\mathrm{a}}$ & $85 \%^{\mathrm{b}}$ & $65 \%$ b,c & $<.001$ \\
\hline Education level & a & b & a & $<.001$ \\
\hline Low & $22 \%$ & $61 \%$ & $36 \%$ & \\
\hline Medium & $47 \%$ & $20 \%$ & $26 \%$ & \\
\hline High & $31 \%$ & $19 \%$ & $38 \%$ & \\
\hline \multicolumn{5}{|l|}{ Employment status } \\
\hline Paid employment & $83 \%^{\mathrm{a}}$ & $35 \%^{\mathrm{b}}$ & $55 \%$ b,c & $<.001$ \\
\hline Full-time job & $55 \%^{\mathrm{a}}$ & $15 \%^{\mathrm{b}}$ & $18 \%^{\mathrm{b}}$ & $<.001$ \\
\hline Change since illness & $20 \%^{\mathrm{a}}$ & $58 \%^{\mathrm{b}}$ & $59 \%^{\mathrm{b}}$ & $<.001$ \\
\hline Disability insurance & $1 \%^{\mathrm{a}}$ & $40 \%^{\mathrm{b}}$ & $32 \%^{\mathrm{b}}$ & $<.001$ \\
\hline
\end{tabular}

Note. Different superscript letters indicate a significant difference with Scheffé test.

prednisolon. Of the $98 \mathrm{MS}$ patients, 40\% experienced fatigue, 25\%leg weakness, $21 \%$ incontinence problems, $16 \%$ pain, and $10 \%$ spasms; $21.7 \%$ of the MS patients used interferon, which reduces the frequency and severity of relapses. Although the chances of psychological disturbance increase with the use of interferon (Drugs and Therapeutics Bulletin (DTB), 1996), we found no significant differences in optimism and depression between patients using interferon and patients not using it.

\section{Measures}

Controllability, optimistic beliefs, coping and adaptation were assessed with the following questionnaires. In all cases, authorized Dutch translations of these questionnaires were used that had proved to be reliable and valid in Dutch populations.

\section{Perceived disease controllability}

By measuring perceived controllability, we were able to ascertain that the three diseases differ significantly with respect to availability of self-care options. Perceived controllability of disease was measured by an adapted version of the Multidimensional Health Locus of Control (MHLC) scale (Halfens \& Philipsen, 1988; Wallston, Wallston, Kaplan, \& Maides, 1978), consisting of 18 items measuring Internal locus of control, External locus of control ascribed to powerful others, and External locus of control ascribed to chance. These items were changed when their content referred to health, being healthy, recovering from illness or preventing illness, and were replaced by the following words: disease, staying ill or free of symptoms, recovering from symptoms, or preventing 
symptoms, respectively. Similarly, revised versions of the MHLC for chronically ill patients have proved to be reliable and valid for use with coronary bypass patients (Fitzgerald, Tennen, Affleck, \& Pransky, 1993), patients with end-stage renal disease (Christensen, Turner, \& Smith, 1991), Dutch RA patients (van Lankveld, 1993) and Dutch MS patients (Fournier et al., 1999).

In the present study, patients were asked to indicate their agreement on a 6-point Likert scale ranging from strongly agree (1) to strongly disagree (6). Alower score means a higher amount of the specified locus of control. Cronbach's $\alpha$ values for the Internal scale, Powerful others scale and Chance scale were $.81, .75$ and .55 , respectively, for the IDDM-sample; .71, .66 and .53, respectively, for the RA sample; and .69, .78 and .59, respectively, for the MS sample group. Although the reliability scores for the Chance scale are borderline, we decided to use this scale in our analyses because it is theoretically relevant for corroborating disease categorizations according to controllability (see, for example, Penninx et al., 1996).

\section{Optimism}

Outcome expectancies were measured by the Revised version of the Life Orientation Test (LOT-R) (Scheier, Carver, \& Bridges, 1994) which consists of six items and four filler items. Participants are asked to indicate their agreement with the items on a 5 -point Likert scale ranging from strongly disagree (0) to strongly agree (4). Scheier et al. (1994) showed that the LOT-R measures optimism as one dimension in an internally consistent way. Cronbach's $\alpha$ values in the present study were .77 for the IDDM sample, 60 for the RA sample and .75 for the MS sample.

Efficacy expectancies were measured by the Generalized Self-Efficacy Scale (Schwarzer, 1993) consisting of 10 items. A higher score reflects more confidence in one's coping capacity and ability to handle difficult situations. The scale is internally consistent and valid (Schwarzer, 1993). Cronbach's $\alpha$ s in the present study were .85 for the IDDM sample, .84 for the RA sample and .87 for the MS sample.

Unrealistic thinking was measured using the Comparative Risk Judgment Rating Forms (Otten, 1995; Weinstein, 1980). Patients are asked to judge their chances of experiencing 15 (non-typical illness-related) situations when compared to the average person of the same age, sex, and with the same kind of disease. Possible responses range from -4 to 4 , and were transformed to 1 to 9 in the analyses. After correcting for low (near zero) item-total correlation (which proved to be unrelated to the concept), 13 of the 15 items were selected for the analyses. The comparative estimates were confirmed to be valid for revealing biases, as can be seen when homosexual men were asked about AIDS (Taylor, Kemeny, Reed, \& Aspinwall, 1991). Cronbach's $\alpha$ s in the present study were .82 for the IDDM sample, .77 for the RA sample and .74 for the MS sample.

\section{Adaptation}

Task-oriented, emotion-oriented and avoidance coping were measured using the short form of the Coping Inventory for Stressful Situations (CISS) (Endler \& Parker, 1994), which consists of 21 items. Task-oriented coping indicates problem solving, emotionoriented coping includes managing the emotions evoked by the stressful situation, and avoidance coping includes seeking other people's company or seeking distraction. The CISS has proved to be a psychometrically sound instrument for measuring coping in Dutch patient samples (e.g. Fournier et al., 1999) and the CISS-21 appears to be valid and reliable in healthy populations (Pisanti, Gagliardi, \& Razzino, 1999). Cronbach's $\alpha$ s 
for the IDDMsample were $.81, .77$ and .78, respectively; for the RAsample they were .78, .72 and .73, respectively; and for the MS sample they were $.80, .78$ and .76, respectively.

The Hospital Anxiety and Depression Scale (HADS) (Zigmond \& Snaith, 1983) a 14item self-report scale was used to measure anxiety and depressive symptoms with seven items measuring anxiety and seven items measuring depression. The HADS is relatively free of criterion contamination by somatic items, which was confirmed in RA patients (Pincus, Griffith, Pearce, \& Isenberg, 1996). The HADS has proved to be reliable and valid in Dutch patient samples (Spinhoven et al., 1997). Cronbach's $\alpha$ s for the IDDM sample were .77 and .73, respectively; for the RA sample they were .71 and .60 , respectively; and for the MS sample .78 and .76 , respectively.

Physical functioning was measured by the physical functioning scale (PF) of the Outcome Study 36-Item Short Form Health Survey (SF-36) (Ware \& Sherbourne, 1992). This scale consists of 10 self-report items and is internally consistent and valid, also in Dutch populations (Van der Zee \& Sanderman, 1993). A lower score means more limitations in physical activities (including mobility range and activity level). Cronbach's $\alpha$ was .72 for the IDDM sample, .89 for the RA sample and .93 for the MS sample.

\section{Severity of the illness}

Disease-specific instruments measured severity of the illness. There is often considerable discrepancy between objective measures of disease severity and the subjective illness experiences (see Dekker, Boot, van der Woude, \& Bijlsma, 1992), and since the present study aims to control for the disease severity experienced by the patients, we used the subjective indicators.

In the IDDMsample, illness severity was measured by the self-reported IDDM-related symptoms checklist, indicating six diabetes-related symptoms, including unstable blood sugar level, impaired vision and decreased sensitivity in feet/hands. Patients were asked to indicate the presence or absence of each symptom by yes (1) versus no (0). The symptoms were significantly related to the severity of hyperglycaemia during the previous 2 months, indicated by the rate of glycosylated haemoglobin $(r=.25$; $p=.04 ; N=69$ ) (Gonder-Frederick \& Cox, 1991).

In the RA sample, illness severity was determined by the self-reported RArrelated symptoms checklist, which consists of 16 RAtrelated symptoms, including stiff joints, pain, fatigue, noduli, and side-effects of medicines. Patients were asked to indicate the presence or absence of each symptom by yes (1) versus no (0). The construct validity was supported by a signific ant correlation with the disease activity score (DAS), which is based on the number of swollen joints (28 joint count), the number of tender joints (28 joint count), an acute phase response measure (erythrocyte sedimentation rate) and the patient's global assessment of disease activity (Scott, van Riel, van der Heijde, \& Studnicka Benke, 1993) ( $r=.49 ; p<.001 ; N=95)$.

In the MS sample, illness severity was measured by the self-reported MS-related symptoms checklist (Gulick, 1988). The checklist measured 26 neurological-related symptoms, which included skeletal functions, kinaesthetic functions, emotions, and head functions. Participants were asked to indicate the frequency with which they have experienced each symptom from never (0) to always (5). To determine the physical symptoms specifically, we removed the four emotion-specific items from the scale. In earlier research, the MS-related symptoms checklist proved to be reliable and valid (Gulick, 1988). In the present study, the construct validity was proven by a significant relation with the expanded disability status scale (Kurtzke, 1983) $(r=.51 ; p<.001$; $N=54$ ), which was determined by the neurologist. 
To compare the disease severity of the sample groups, the symptom checklists of the IDDM, RA and MS sample groups were used. Multiplying the IDDM score (by 22/6×5) and the RAscore (by $22 / 16 \times 5$ ) makes the range of the scales commensurate to the MS score.

\section{Analyses}

First, the hypothesized three-dimensional model of optimism was investigated in the three patient samples by means of maximum likelihood confirmatory factor analysis in the three separate samples (LSREL 8.12) (Jöreskog \& Sörbom, 1996). For each sample, we analysed whether optimism is better represented by a three factor model than a onefactor model representing optimism in general, or a two-factor model presenting functional and defensive optimism (Schwarzer, 1994). The input was the covariance matrix based on scaled means and SDs for the measures $(m=0 ; \mathrm{SD}=1)$. Measurement errors of the independent variables were estimated a priori using Cronbach's $\alpha$, a measure of reliability. Subsequently, the measurement errors $\left(1-\right.$ Cronbach's $\left.\alpha * \mathrm{SD}^{2}\right)$ were specified in the input file (Jöreskog \& Sörbom, 1996). Next, we analysed whether the optimism model represents optimism in a similar way in each disease, first by testing the similarity in covariances of the optimism measures between IDDM, RA, and MS samples, and second by testing the similarity in measurement errors of the optimism measures. Only latent variables were used in these analyses.

In order to test the assumption of normality, the variables were evaluated in terms of skewness. The skewness of all variables except the physical functioning scale (PF) in the IDDM sample was between -1.5 and +1.5 . As the distribution of the PF scale was not severely skewed (skewness $=-2.5, \mathrm{SD}=2.0$ ), all variables proved to have an acceptable normal distribution (Chou \& Bentler, 1995).

Second, multi-sample analysis was used by means of path modelling of observed variables (LSREL 8.12) to investigate whether the role of positive outcome expectancies, efficacy expectancies and unrealistic thinking varies with the controllability of disease. Multi-sample analyses were based on a theoretical adaptation model based on the coping model of Lazarus and Folkman (1984), assuming that the three optimistic beliefs are related to depression, anxiety and physical functioning, directly as well as indirectly via coping strategies. The impact of the experienced disease severity (physical symptoms) was controlled for and the measurement errors for anxiety and depression were allowed to covary, as were the measurement errors of task-oriented coping and emotion-oriented coping.

We systematically investigated whether the three optimistic beliefs are differently related to physical functioning, anxiety and depression, with increasing uncontrollability of disease. In the first step we investigated whether the three optimistic beliefs were indirectly related to anxiety, depression and physical functioning by using more task-oriented coping and less emotion-oriented coping. Paths, covariance matrices and measurement errors were allowed to differ for the three diseases. Paths were systematically evaluated by means of parameter estimates, standardized residuals, and the measures of overall fit provided by the LSREL program $\left(\chi^{2}\right.$, RMSEA, GFI) ${ }^{1}$ (Jöreskog,

\footnotetext{
'Several measures indicate the fit of the model, three of which are applied in the present study. (I) $\chi^{2}$ indicates the discrepancy between the covariance matrix predicted by the model and the observed covariance matrix; a significant discrepancy ( $p$ value) results in model rejection. (2) Root mean square of approximation (RMSEA) measures the discrepancy per degree of freedom, and assesses the degree of approximation in the population. A value $<.05$ indicates a close fit. (3) Goodness of fit index (GFI) measures the fit of the model compared to no model at all. Based on the adjusted GFI, the value should be $>.92$.
} 
1993), and paths were omitted when non-significant. In the second step, we investigated whether the three optimistic beliefs were directly related to depression, anxiety and physical functioning on top of the existing indirect paths, and we evaluated the paths in a fashion similar to the first step.

In the final step, we observed whether the different relations of optimistic beliefs to the outcome measures are related to differences in controllability of the three diseases. When effects of optimistic beliefs on the outcome measures were stronger in IDDM, less strong in RA and least strong in MS (or in the revised direction), it can be concluded that the relation of optimistic beliefs to outcome measures changes with disease controllability. Only significant results will be presented.

\section{Results}

\section{Differences in optimism and adaptation between type I diabetes mellitus, RA and MS patients}

Mean differences between the three patient samples in outcome expectancies (LOT-R), efficacy expectancies (Generalized Self-Efficacy) and positive unrealistic thinking (unrealistic optimism) are absent (Table 2). The present results report somewhat higher positive outcome expectancies than the norms presented by Scheier et al. (1994) in healthy individuals $(M=14.3 ; \mathrm{SD}=4.3)$ and heart bypass patients $(M=15.2$; $\mathrm{SD}=4.0)$. There were no differences in the extent of efficacy expectancies in comparison with norms for healthy populations (Schwarzer, 1993). As a group, patients use significantly more positive unrealistic thinking. This is determined by comparing the group mean of each sample with the scale mean indicating realistic thinking (scale mean $=65)($ Weinstein, 1980).

The present samples showed a comparable extent of depressive symptoms compared with Dutch general practice patients $(M=3.7 ; \mathrm{SD}=3.4)$, while the anxiety shown by our samples was somewhat lower $(M=6.2 ; \mathrm{SD}=3.8)$ and more similar to the anxiety level of the Dutch general population $(M=5.1 ; \mathrm{SD}=3.6)$ (Spinhoven et al., 1997).

There are significant differences, however, between the IDDM sample and the RA/ MS samples in adaptation. IDDM patients use significantly more task-oriented coping, are less depressed, and their physical functioning is significantly better, compared with RA and MS patients. This may be partly attributed to the higher rate of physical symptoms reported by MS and RA patients. The three sample groups reported similar levels of anxiety.

\section{Controllability of chronic disease}

Table 2 shows that IDDM patients perceived a significantly higher level of internal locus of control than RA and MS patients, who reported a significantly higher external locus of control. RA patients reported more than IDDM and MS patients that their health is not contingent upon their own behaviour but controlled by their doctor. MS patients reported more than RAand IDDM patients that their health is not contingent upon their own behaviour but upon chance factors, while RA patients in turn reported more than IDDM patients that their health is controlled by chance factors. These comparisons were controlled for differences in experienced disease severity, age and disease duration, which did not change the findings. 
Table 2. Differences in measures between the IDDM, RA and MS sample groups

\begin{tabular}{|c|c|c|c|c|c|c|c|}
\hline & \multicolumn{2}{|c|}{$\operatorname{IDDM}(N=104)$} & \multicolumn{2}{|c|}{$\mathrm{RA}(N=95)$} & \multicolumn{2}{|c|}{ MS $(N=98)$} & \multirow{2}{*}{$\frac{\text { ANOVA }}{p}$} \\
\hline & Mean & SD & Mean & SD & Mean & SD & \\
\hline \multicolumn{8}{|l|}{ Optimism } \\
\hline Life Orientation Test-Rev & 16.7 & 3.5 & 16.4 & 3.5 & 16.6 & 3.8 & .83 \\
\hline Generalized Self-Efficacy & 30.7 & 4.2 & 30.0 & 4.2 & 29.3 & 5.3 & .10 \\
\hline Unrealistic optimism & 77.0 & 13.2 & 75.8 & 13.6 & 75.7 & 13.4 & .76 \\
\hline \multicolumn{8}{|l|}{ CISS-2I } \\
\hline Task-oriented coping & $21.9^{\mathrm{a}}$ & 4.9 & $19.7^{b}$ & 4.8 & $19.8^{\mathrm{b}}$ & 5.0 & $<.01$ \\
\hline Emotion-oriented coping & 13.7 & 4.4 & 13.0 & 3.8 & 13.3 & 4.1 & .53 \\
\hline Avoidance coping & 16.6 & 5.3 & 15.4 & 4.4 & 15.3 & 4.7 & .11 \\
\hline \multicolumn{8}{|l|}{ HADS } \\
\hline Depression & $2.7^{\mathrm{a}}$ & 2.7 & $3.6^{\mathrm{b}}$ & 2.5 & $3.7^{\mathrm{b}}$ & 3.4 & $<.05$ \\
\hline Anxiety & 4.9 & 3.4 & 5.4 & 3.7 & 5.4 & 3.7 & .55 \\
\hline SF-36 physical functioning & $28.7^{\mathrm{a}}$ & 2.1 & $21.3^{b}$ & 4.7 & $21.5^{\mathrm{b}}$ & 5.9 & $<.001$ \\
\hline Physical symptoms & $15.7^{\mathrm{a}}$ & 16.8 & $31.0^{\mathrm{b}}$ & 20.0 & $31.2^{\mathrm{b}}$ & 15.6 & $<.001$ \\
\hline \multicolumn{8}{|l|}{ Health Locus of Control } \\
\hline Internal LOC* & $15.8^{\mathrm{a}}$ & 4.8 & $22.0^{\mathrm{b}}$ & 5.1 & $21.5^{\mathrm{b}}$ & 5.1 & $<.001$ \\
\hline \multicolumn{8}{|l|}{ External LOC } \\
\hline Powerful others* & $27.0^{\mathrm{b}}$ & 4.7 & $23.9^{\mathrm{a}}$ & 4.9 & $27.5^{\mathrm{b}}$ & 5.4 & $<.001$ \\
\hline Chance* & $25.4^{\mathrm{a}}$ & 4.6 & $21.7^{b}$ & 4.6 & $20.0^{b, c}$ & 5.2 & $<.001 ;<.05$ \\
\hline
\end{tabular}

Notes. Different superscript letters indicate significant difference with the Scheffé test.

*A lower score means a higher amount of the specific control scale.

These results indicate that perceived controllability is parallel to the actual controllability, and demonstrate that IDDM could be characterized by high controllability, RA by moderate controllability (more controllable by their doctor than by their own behaviour), and MS by low controllability (more chance related than controllable by doctor and own behaviour).

\section{Confirming the three-dimensional structure of optimism}

The earlier reported three-dimensional structure of optimism (Fournier et al., 1999) was confirmed in the present samples, showing that the optimism concept is best represented by outcome expectancies, efficacy expectancies and unrealistic thinking $\left(\chi^{2}(6)=7.44 ; p=.28\right)$ (see Table 3 ). Table 3 shows that the three-dimensional model showed a better fit to the data than both the one-dimensional model (optimism) and the two-dimensional one (functional versus defensive). Moreover, the three dimensions of optimism were similarly related to each other in the three samples, according to the good fit $\left(\chi^{2}(12)=16.67 ; p=.16\right)$, and the comparable contribution of the three samples to the $\chi^{2}$ (IDDM: $24 \%$ RA: $36 \%$ MS: $40 \%$ ).

\section{Path modelling of the adaptiveness of optimistic beliefs in IDDM, RA and MS patients}

Table $4 a-c$ shows the correlations between optimism and coping for each particular patient sample and clearly demonstrates the absence of even a weak association 


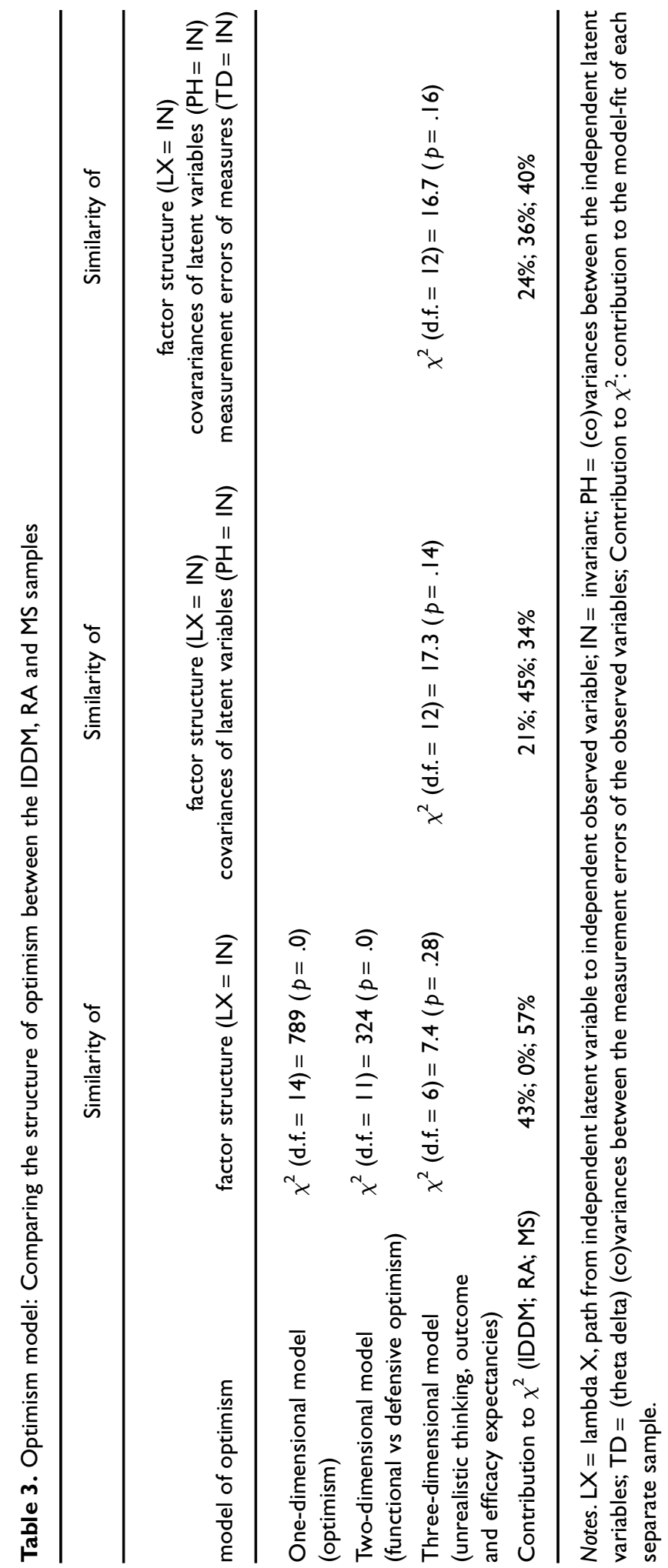




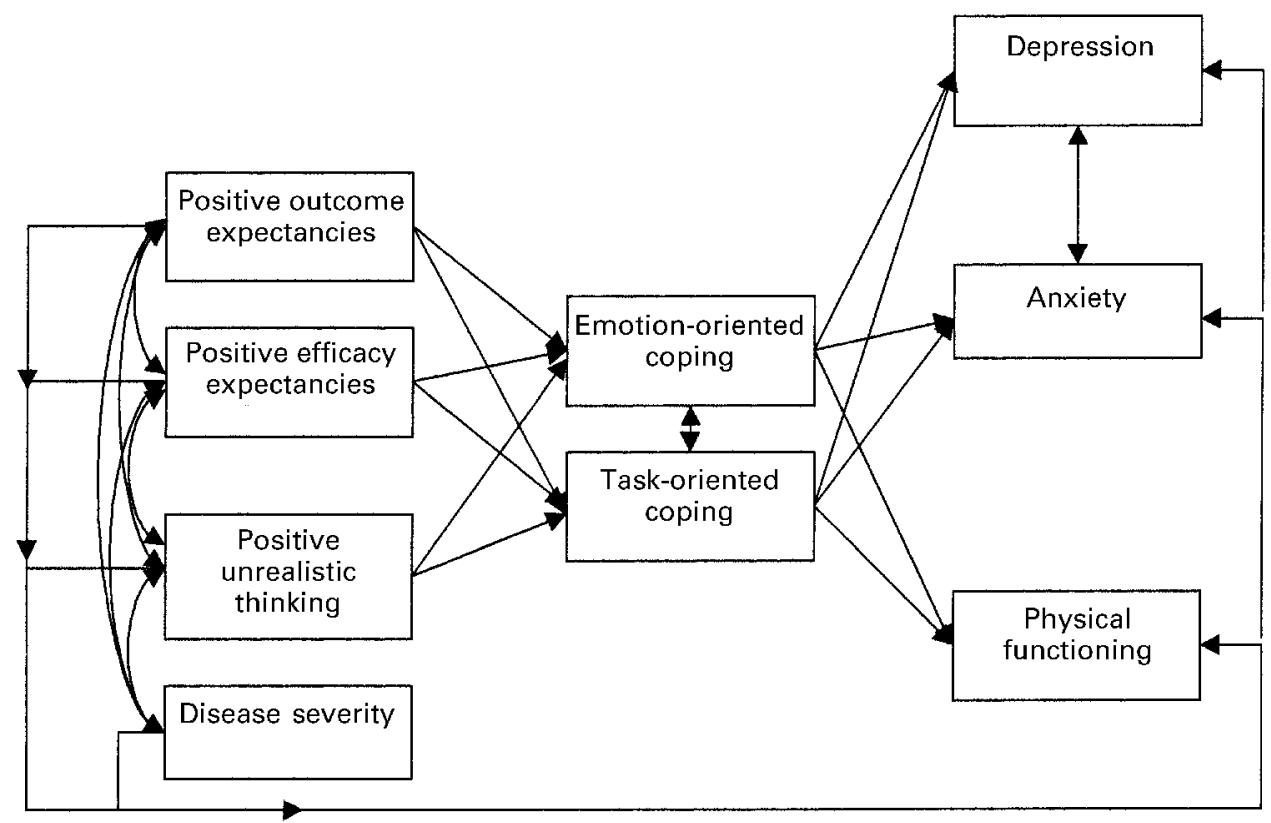

Figure I. Theortical adaptation model for chronic diseases.

between optimism and avoidance coping. Therefore, avoidance coping was excluded from the analyses.

Multi-sample analysis was based on the theoretical adaptation model (see Figure 1). As can be seen in Figure 2, optimistic beliefs across diseases show similarities as well as differences in their relation to adaptation in different chronic diseases. We will first describe the disease-generic (similarities) and disease-specific (differences) paths, and will then investigate whether disease-specific paths could be attributed to the differences in controllability of the three chronic diseases.

In each disease, positive outcome expectancies are directly related to less depression, and are directly as well as indirectly related to less anxiety by using less emotionoriented coping. In contrast to the theoretical adaptation model, positive outcome expectancies are not related to physical health or to task-oriented coping. Furthermore, in each disease, positive efficacy expectancies are related to more use of task-oriented coping (see Figure 2).

Disease-specific relations were found for the impact of positive efficacy expectancies, unrealistic thinking and coping strategies on the outcome measures. More particularly, positive efficacy expectancies are directly related to less anxiety in IDDM, are not related to mental health in RA, and are indirectly related to less anxiety and depression in MS by using less emotion-oriented coping. Positive efficacy expectancies are indirectly related to better physical functioning in IDDM by using more taskoriented coping, while they are not related to physical health in RA. In MS, positive efficacy expectancies are related to worse physical functioning only when task-oriented coping is not possible. Positive unrealistic thinking is not related to mental or physical health in IDDM, while positive unrealistic thinking is directly related to better physical functioning in RA, and it is indirectly related to better physical functioning in MS by using more task-oriented coping. In contrast to the theoretical adaptation model, 
Marijda Fournier et al.

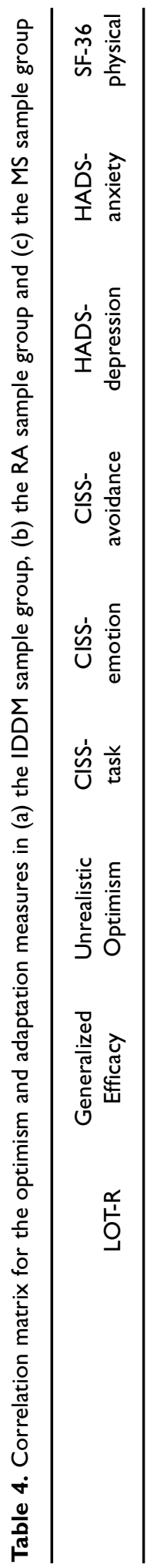

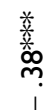

$$
\begin{aligned}
& \text { ำ }
\end{aligned}
$$

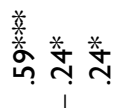

$$
\begin{aligned}
& m=\infty
\end{aligned}
$$

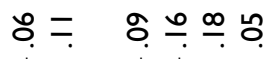

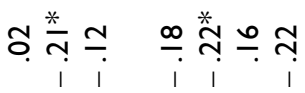

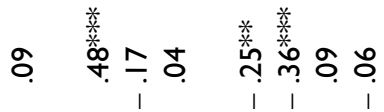

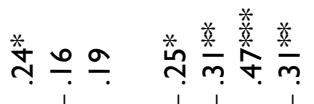

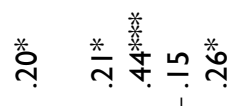

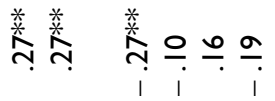

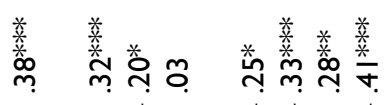

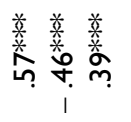

$8 \stackrel{8}{\circ} \div$ 


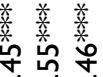

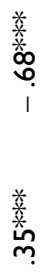

ริ กิ ซิ ชิ

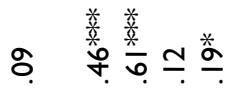

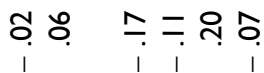

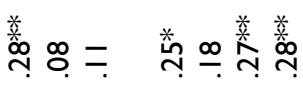

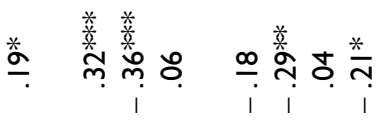

荅蒡

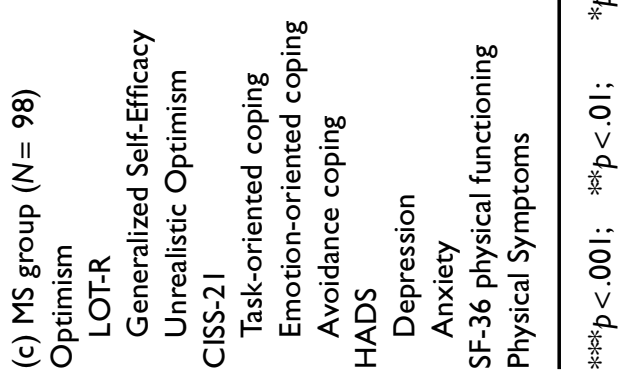




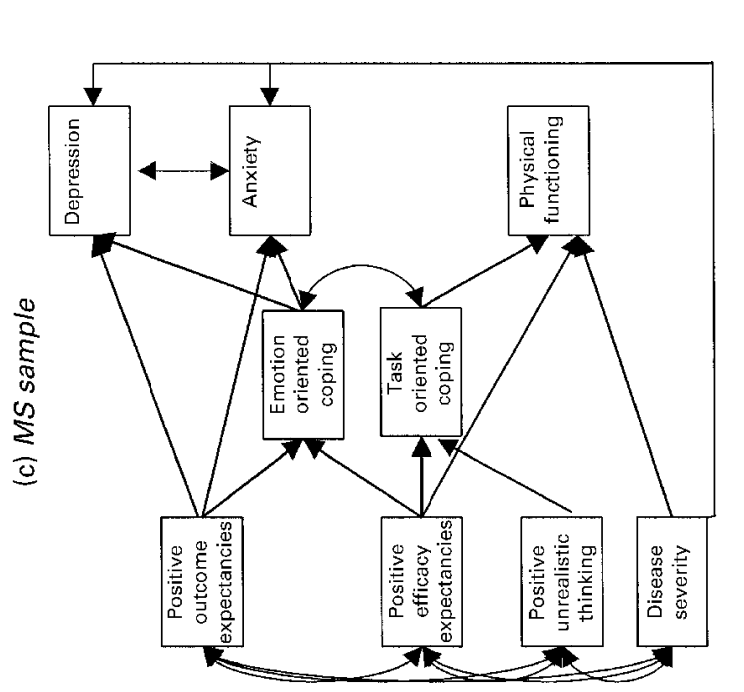

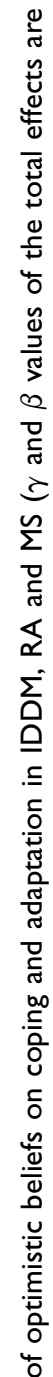
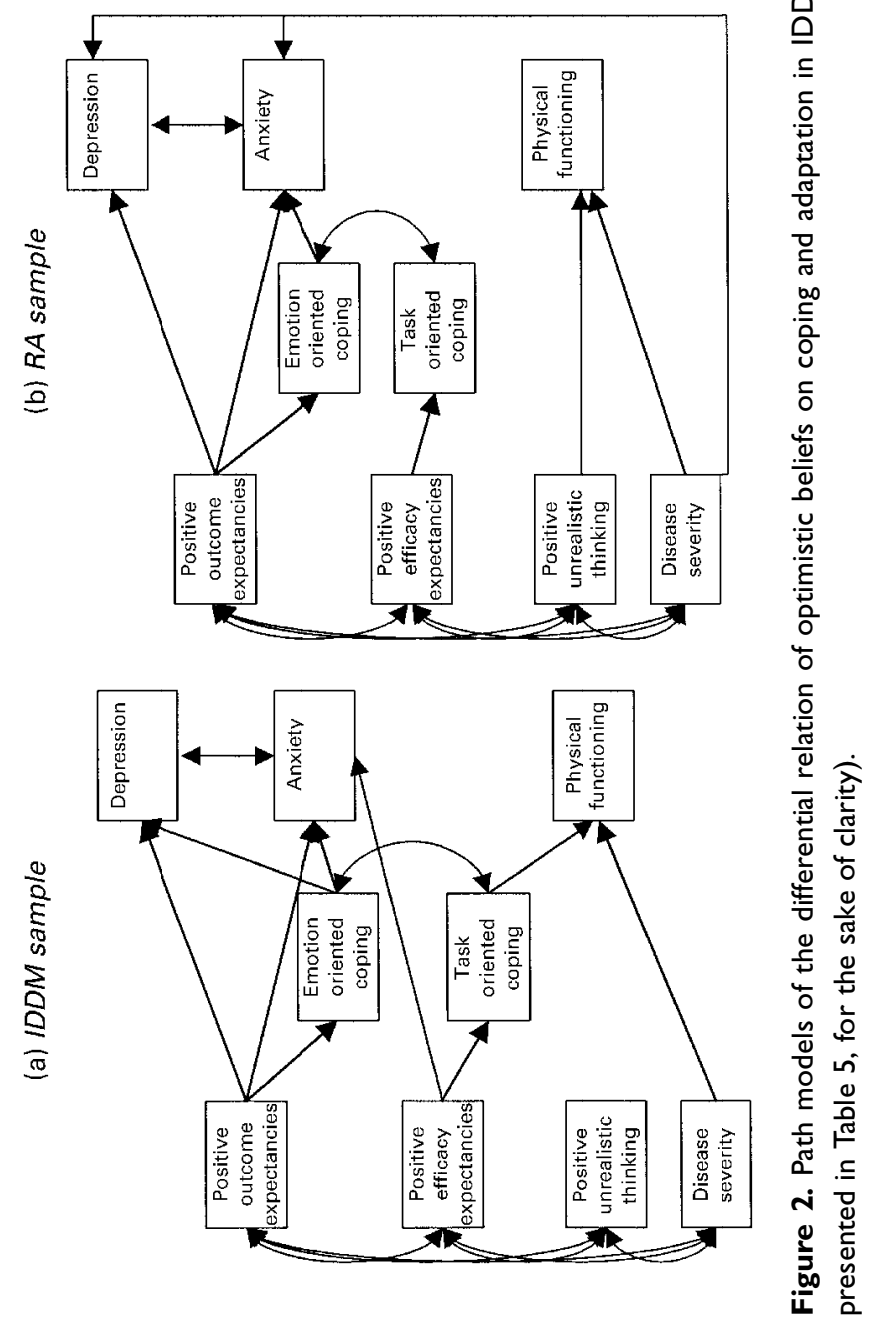
positive unrealistic thinking is not related to mental health in any disease. The model fits the data satisfactorily $\left(\chi^{2}(53)=63.3 ; p=.16\right.$; $\left.\mathrm{RMSEA}=0.026 ; \mathrm{GFI}=.95\right)$.

Table 5 shows the total effects of optimistic beliefs (direct and indirect via the use of coping strategies) on depression, anxiety and physical functioning for each disease. When observing the total effects, it appears that the differential relations of positive efficacy expectancies and unrealistic thinking to physical functioning are attributable to the disease controllability of IDDM, RA and MS. In line with our expectations, the adaptiveness of positive efficacy expectancies to physical functioning increases with the controllability of chronic disease, while the impact of positive unrealistic thinking decreases. More particularly, efficacy expectancies are positively related to physical functioning in IDDM, non-significantly related in RA, and are negatively related to physical functioning in MS. In contrast, positive unrealistic thinking is not related to physical functioning in IDDM, and is positively related to physical functioning in RA and MS.

Differences between diseases in the relations of positive efficacy expectancies to anxiety and depression are unrelated to the controllability of disease and may be attributed to the differential function of emotion-oriented coping in each disease.

\section{Discussion}

In the present study, we examined the role of optimism in adaptation to type 1 diabetes mellitus, rheumatoid arthritis, and multiple sclerosis. Having confirmed a three-dimensional approach to optimism in chronic diseases, we explored whether the role of optimism in adaptive processes depends on the available options for self-care and control of chronic disease. Our results strongly suggest that the three dimensions of optimism - positive outcome expectancies, positive efficacy expectancies, and positive unrealistic thinking - relate to adaptation to chronic illness in different ways, depending on the extent of controllability by self-care to manage the specific disease. Our data also show that the role of optimism in mental health is independent of the disease controllability by self-care. This is in accordance with earlier studies demonstrating that the relationship between optimistic expectancies and mental health does not depend on the level of controllability of the chronic disease (e.g. Penninx et al., 1998). In addition, our results show that positive unrealistic thinking appears especially beneficial to physical function in cases of limited self-care options. In contrast, positive expectancies of one's coping ability are adaptive in largely controllable disease where self-care is required, and maladaptive for patients dealing with a largely uncontrollable chronic disease where self-care is limited. The impact of positive outcome expectancies is restricted to mental health. Disease specificity aspects of the impact of optimism on adaptation may be attributed to a differential role of emotion-oriented coping in each disease.

Before we discuss these findings, we want to point to a number of critical points associated with the study. First, the cross-sectional nature of the study makes it difficult to draw firm conclusions about the direction of the relationship between optimism and adaptation. However, prospective studies of optimism have suggested that RA patients (Brenner et al., 1994) and cancer patients (Carver et al., 1993) may benefit from positive outcome expectancies over a longer period of time. Also, efficacy expectancies have proved helpful over a longer period of time in diabetic patients (Kavanagh, Gooley, \& Wilson, 1993), RA patients (Lorig, Mazonson, \& Holman, 1993), and MS patients (Barnwell \& Kavanagh, 1997). The long-term effect of positive unrealistic thinking is 
Marijda Fournier et al.

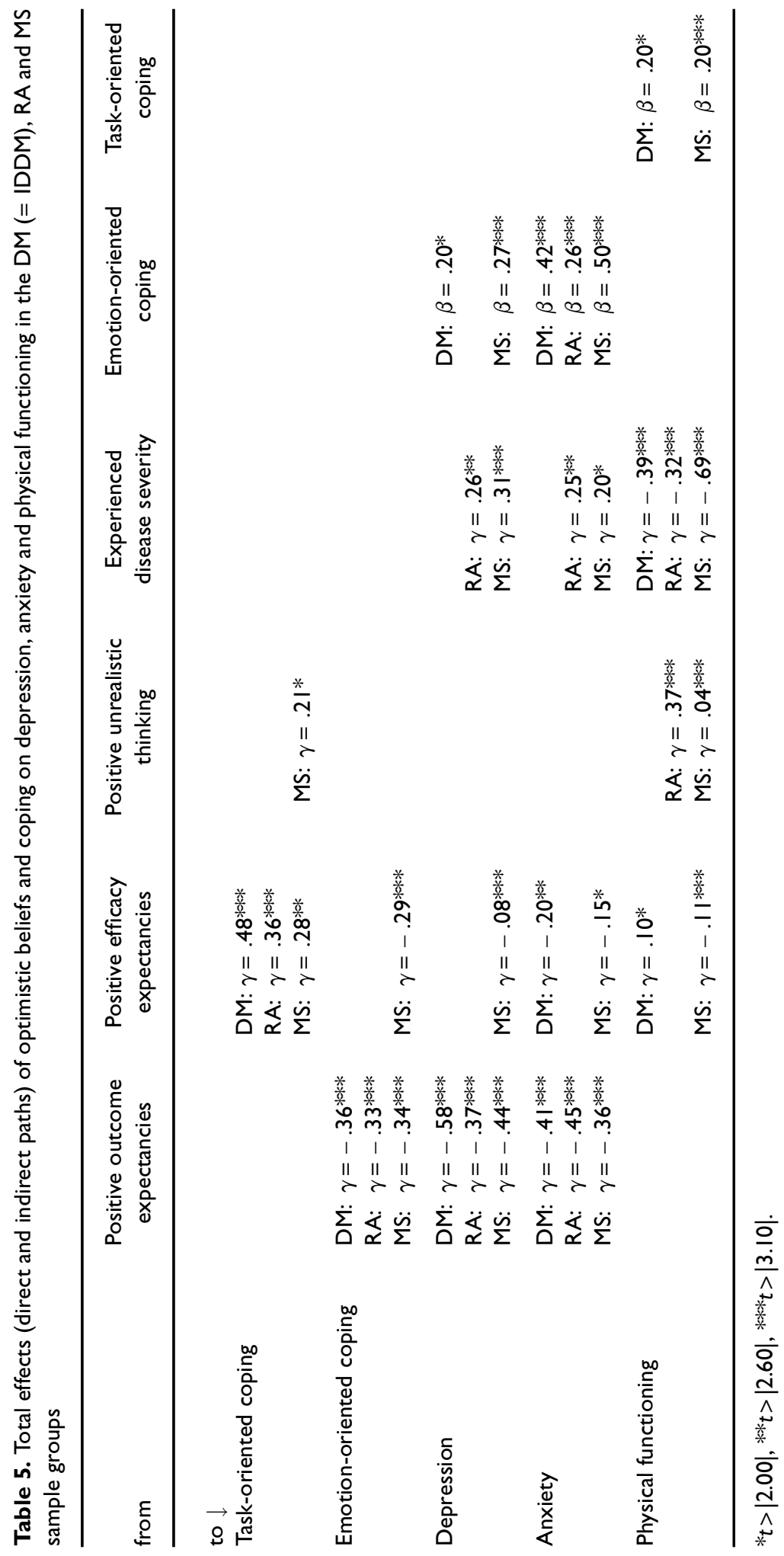


still unknown, however. It is our intention to analyse the benefits and costs of the three optimistic beliefs over an extended period of chronic disease.

A second limitation of this study is that the differences between the IDDM, RA and MS patients may be explained by discrepancies in demographic and illness characteristics rather than the actual controllability of the diseases. This is unlikely, however, as the IDDM patients perceived more control over their health than the RA patients, who in turn experienced more control than the MS patients, even after controlling for the degree of disease severity experienced. Although RA and MS patients reported to a similar extent that their disease could not be controlled by their own behaviours, RA patients perceived that doctors are able to control their disease, while MS patients expected that nobody (neither doctors nor themselves) could control their disease, which depended on chance. Moreover, the differences in physical state and disease duration were the result of qualitative differences between the diseases, and the patients represented those who were moderately physically impaired by their disease during adulthood. Thus, the chronically ill patients included in the study are largely comparable and the main difference is in the level of controllability of their disease. This was substantiated by several studies demonstrating that actual controllability is an important factor for explaining psychological processes in varying chronic diseases that are basically separate medical entities (Felton et al., 1984; Penninx et al., 1996).

Despite these limitations, the present study is the first to systematically explore the role of different aspects of optimism in relation to coping with chronic illness. Moreover, we have attempted to interpret the differential role of optimism in relation to the self-care options of chronic disease. The finding that chronically ill patients whose illness is controllable benefit the most from positive efficacy expectancies is consistent with the literature, showing that efficacy expectancies contribute to skilful self-care behaviour and to physical and mental health (Lorig et al., 1989). The present study also showed that chronically ill patients who have limited control over their disease (as is the case in MS) benefit from positive efficacy expectancies only when they are able to cope with illness in a task-oriented manner. In line with the literature, it appears that believing that one is able to deal with one's own health aspects when they are in fact uncontrollable increases the risk for maladaptation and frustration (Affleck, Tennen, Pfeiffer, \& Fifield, 1987). It can be stated, then, that positive efficacy expectancies are only beneficial when they relate to controllable aspects of the disease, such as specific behaviours that allow patients to engage in daily activities (task-oriented coping) (Barnwell \& Kavanagh, 1997).

As expected, positive efficacy expectancies were not related to physical functioning in RA, either directly or indirectly via task-oriented coping. As RApatients were found to appraise their health to be controllable by their doctor more than by their own behaviour, they apparently did not benefit from their task-oriented coping or from positive efficacy expectancies. In contrast, as MS patients cannot rely on a doctor to control their health, they have to rely on themselves and on task-oriented coping, even though they think that their health is dependent on chance.

In case of more uncontrollable circumstances, patients benefit from positive unrealistic thinking. This is consistent with the study of Taylor, Helgeson, Reed, and Skokan (1991) among AIDS patients, showing that positive illusions were substantially more strongly related to adjustment in patients with poor health (less controllable) than those with better health. This suggests that positive unrealistic thinking is selfprotective, in the sense that it prevents awareness of threatening information and therefore contributes to adaptation. Of course, the role of unrealistic optimism in physical 
health has been much more questionable (see Weinstein, 1987). However, contrary to our expectations, positive unrealistic thinking did not threaten the physical health of the patients in the present study. This apparent contradiction may be clarified by the theory of Taylor and Gollwitzer (1995) who have argued that the adaptiveness of positive unrealistic thinking depends on the right point of time. Before a decision to act is made, realism will be necessary to carefully consider the pros and cons and to address attainable goals (= deliberate mindset). After the decision, people move into an implemental mindset where unrealistic optimism is necessary to carryout their plans (Schwarzer, 1999). Thus, it is likely that over an extended period of chronic disease, positive unrealistic thinking may threaten physical functioning by interfering with making the right decisions.

Consistent with the literature on behavioural self-regulation (Carver \& Scheier, 1998), the adaptiveness of positive outcome expectancies was independent of the degree of controllability of the disease. Apparently, positive outcome expectancies help people to remain mentally engaged, even in serious conditions beyond their control, and promote psychosocial functioning. Our results suggest that positive outcome expectancies help patients to accept their situation, directly and indirectly by using less emotion-oriented coping. Nevertheless, RA studies have demonstrated that wishful thinking (which is one aspect of emotion-oriented coping) is independently relevant for mental health (Brenner et al., 1994; Long \& Sangster, 1993). Thus, other aspects of emotion-oriented coping (such as less blaming yourself or not feeling confused) are used by patients with positive outcome expectancies.

Disease-specific aspects of adaptation to chronic disease that could not be explained by differences in the controllability of chronic disease are related to the differential function of emotion-oriented coping in each disease. Both IDDM patients and MS patients report less depression by using less emotion-oriented coping, while RApatients do not benefit from emotion-oriented coping, which may be also explained by their expectation that their health is controlled by their doctor, and thereby invalidating the worth of their own coping possibilities.

The present findings could be applied beyond specific chronic diseases and aim to understand adaptation in a wider context. Earlier studies found that psychosocial responses to chronic diseases are independent of diagnosis, and could be explained by differences in functional disability and controllability of the disease (Felton et al., 1984; Penninx et al., 1996). Although we did not find control-related differences for mental health, physical health benefits differently from optimism related to self-care options. How ever, further research is nec essary to clarify these different functions of optimism.

\section{Acknowledgements}

The authors acknowledge all patients who participated in the study and all members of the research group. In particular, the authors thank Dr. G. E M. G. Storms, internist at the Diabetic Centre, Bilthoven; Dr. A A A. Westgeest, rheumatologist at Diaconessenhuis, Eindhoven; Dr. S. T. F. M. Frequin, neurologist at the St. Antonius Hospital Nieuwegein; and Dr. J. E. C. Bromberg, neurologist at the Universitair Medical Centre, Utrecht, for their significant contributions to data collection. The authors are grateful to Dr. C. V. Dolan, University of Amsterdam, for his kind advice on LSREL analyses.

\section{References}

Affleck, G., Tennen, H, Pfeiffer, C., \& Fifield, J. (1987). Appraisals of control and predictability in adapting to a chronic disease. Journal of Personality and Social Psychology, 53, 273-279. 
Antonak, R. F, \& Livneh, H. (1995). Psychosocial adaptation to disability and its investigation among persons with multiple sclerosis. Social Science and Medicine, 40, 1099-1108.

Arnett, F. C., Edworthy, S. M., Block, D. A, McShane, D. J., Fries, J. F, Cooper, N. S., Healey, L A, Kaplan, S. R. Liang, M. H, Luthra, H. S., Medsger, T. A, Mitchell, D. M., Neustadt, D. H, Pinals, R. S., Schaller, J. G., Sharp, J. T., Wilder, R. L, \& Hunder, G. G. (1988). The American Rheumatism Association 1987 Revised Criteria for the Classification of Rheumatoid Arthritis. Arthritis and Rheumatism, 31, 315-324.

Bandura, A (1988). Self-regulation of motivation and action through goal systems. In V. Hamilton, G. H Bower, \& N. H Frijda (Eds.), Cognitive perspectives on emotion and motivation (pp. 37-61). Dordrecht: Kluwer Academic Publishers.

Barnwell, A. M. \& Kavanagh, D. J. (1997). Prediction of psychological adjustment to multiple sclerosis. Social Science and Medicine, 45, 411-418.

Brenner, G. F., Melamed, B. G., \& Panush, R. S. (1994). Optimism and coping as determinants of psychosocial adjustment to rheumatoid arthritis. Journal of Cinical Psychology in Medical Settings, 1, 115-134.

Carver, C. S., Pozo, C., Harris, S. D., Noriega, V., Scheier, M. F., Robinson, D. S., Ketcham, A S., Moffat, F. L, \&Clark, K. C. (1993). How coping mediates the effect of optimism on distress: A study of women with early stage breast cancer. Journal of Personality and Social Psychology, 65, 375-390.

Carver, C. S., \& Scheier, M. F. (1994). Optimism and health-related cognition: What variables actually matter? Psychology and Health, 9, 191-195.

Carver, C. S. \& Scheier, M. F. (1998). On the self-regulation of behavior. New York: Cambridge University Press.

Cassileth, B. R., Lusk, E. J., Strouse, T. B., Miller, D. S., Brown, L L, Cross, P. A., \& Tenaglia, A. N. (1984). Psychosocial status in chronic illness: Acomparative analysis of six diagnostic groups. New England Journal of Medicine, 311, 506-511.

Chou, C. P., \& Bentler, P. M. (1995). Estimates and tests in structural equation modeling. In R. H. Hoyle (Ed.), Structural equation modeling: Concepts, issues and applications (pp. 37-55). Newbury Park, CA: Sage.

Christensen, A. J., Turner, C. W., \& Smith, T. W. (1991). Health locus of control and depression in end-stage renal disease. Journal of Consulting and Cinical Psychology, 59, 419-424.

Cox, D. J., Gonder-Frederick, L, \& Saunders, J. T. (1991). Diabetes: Clinical issues and management. In J. J. Sweet, R. H Rozensky, \& S. M. Tovian (Eds.), Handbook of clinical psychology in medical settings (pp. 473-495). New York: Plenum Press.

Dekker, J., Boot, B., van der Woude, L H. V., \& Bijlsma, J. W. J. (1992). Pain and disability in osteoarthritis: A review of biobehavioral mechanisms. Journal of Behavioral Medicine, 15, 189-214.

DTB (1996). Interferon beta-1b - hope or hype? Drug and Therapeutics Bulletin, 34, 9-14.

ECDCD (1997). Report of the Expert Committee on the Diagnosis and Classification of Diabetes Mellitus. Diabetes Care, 20, 1183-1197.

Eitel, P., Hatchett, L, Friend, R., Griffin, K. W., \& Wadhwa, N K. (1995). Burden of self-care in seriously ill patients: Impact on adjustment. Health Psychology, 14, 457-463.

Endler, N. S., \& Parker, J. D. A. (1994). Assessment of multidimensional coping: Task, emotion and avoidance strategies. Psychological Assessment, 6, 50-60.

Epping-Jordan, J. E, Compas, B. E, Osowiecki, D. M., Oppedisano, G., Gerhardt, C., Primo, K., \& Krag, D. N. (1999). Psychological adjustment to breast cancer: Processes of emotional distress. Health Psychology, 18, 315-326.

Felton, B. J., Revenson, T. A., \& Hinrichsen, A. (1984). Stress and coping in the explanation of psychological adjustment among chronically ill adults. Social Science and Medicine, 18, 889898.

Fitzgerald, T. E., Tennen, H, Affleck, G., \& Pransky, G. S. (1993). The relative importance of dispositional optimism and control appraisals in quality of life after coronary artery bypass surgery. Journal of Behavioral Medicine, 16, 25-43. 
Fournier, M, de Ridder, D. T. D., \& Bensing, J. (1999). What does optimism mean? Optimism and adaptation to multiple sclerosis. Journal of Behavioral Medicine, 22, 303-326.

Gonder-Frederick, L A, \& Cox, D. J. (1991). Symptom perception, symptom beliefs, and blood glucose discrimination in the self-treatment of insulin-dependent diabetes. In J. A Skelton \& R. T. Croyle (Eds.), Mental representations in bealth and illness (pp. 220-246). New York: Springer.

Gulick, E. E. (1988). The self-administered ADL scale for persons with multiple sclerosis. In C. Waltz \& O. Strickland (Eds.), The measurement of clinical and educational outcomes in nursing (pp. 128-159). New York: Springer.

Halfens, R, \& Philipsen, H (1988). Een gezondheidsspecifieke beheersingsoriëntatieschaal. Validiteit en betrouwbaarheid van de MHLC. T. v. Sociale Gezondheidszorg, 66, 399-403.

Heinze, E. \& Thon, A (1983). Honeymoon period in insulin-dependent diabetes mellitus. Pediatrician, 12, 208-212.

Hochberg, M. C., Chang, R. W., Dwosh, I., Lindsey, S., Pincus, T., \& Wolfe, F. (1992). The American College of Rheumatology 1991 Revised Criteria for the classification of global functional status in rheumatoid arthritis. Arthritis and Rheumtism, 35, 498-502.

Jöreskog, K. G. (1993). Testing structural equation models. In K. A. Bollen \& J. S. Long (Eds.), Testing structural equation models (pp. 249-316). Newbury Park, CA: Sage Publications.

Jöreskog, K. G., \& Sörbom, D. (1996). LISREL8: User's Reference Guide. Chicago: Scientific Software International.

Kavanagh, D. J., Gooley, S., \& Wilson, P. H (1993). Prediction of adherence and control in diabetes. Journal of Behavioral Medicine, 16, 509-522.

Kurtzke, J. F. (1983). Rating neurologic impairment in multiple sclerosis: An expanded disability status scale (EDSS). Neurology, 33, 1444-1452.

Lazarus, R. S., \& Folkman, S. (1984). Stress, appraisal, and coping. New York: Springer.

Long, B. C., \& Sangster, J. I. (1993). Dispositional optimism/pessimism and coping strategies: Predictors of psychosocial adjustment of rheumatoid and osteoarthritis patients. Journal of Applied Social Psychology, 23, 1069-1091.

Lorig, K., Seleznick, M. Lubeck, D., Ung, E, Chastain, R. L, \&Holman, H. R. (1989). The beneficial outcomes of the arthritis self-management course are not adequately explained by behavior change. Arthritis and Rheumatism, 32, 91-95.

Lorig, K. R., Mazonson, P. D., \& Holman, H R. (1993). Evidence suggesting that health education for self-management in patients with chronic arthritis has sustained health benefits while reducing health care costs. Arthritis and Rheumatism, 36, 439-446.

Miedema, H. S., van der Linden, S. M., Rasker, J. J., \& Valkenburg, H. A (1998). National database of patients visiting rheumatologists in the Netherlands: The standard diagnosis register of rheumatic diseases. A report and preliminary analysis. British Journal of Rheumatology, $37,555-561$.

Otten, W. (1995). Optimism. Dissertation, University of Amsterdam.

Paty, D. W., \& Poser, C. M. (1984). Clinical symptoms and signs of multiple sclerosis. In C. M. Poser (Ed.), The diagnosis of multiple sclerosis (pp. 27-43). New York: Thieme-Stratton.

Penninx, B. W. J. H. Beekman, A. T. F., Ormel, J., Kriegsman, D. M. W., Boeke, A. J. P., van Eijk, J. Th. N. \& Deeg, D. J. H. (1996). Psychological status among elderly people with chronic diseases: Does type of disease play a part? Journal of Psychosomatic Research, 40, 521-534.

Penninx, B. W. J. H. van Tilburg, T., Boeke, A. J. P., Deeg, D. J. H., Kriegsman, D. M. W., \& van Eijk, J. Th. M. (1998). Effects of social support and personal coping resources on depressive symptoms: Different for various chronic diseases? Health Psychology, 17, $551-558$.

Pincus, T., Griffith, J., Pearce, S., \& Isenberg, D. (1996). Prevalence of self-reported depression in patients with rheumatoid arthritis. British Journal of Rheumatology, 35, 879-883.

Pisanti, R, Gagliardi, M. P., \& Razzino, S. (1999). Coping strategies among secondary school teachers: Acontribution concerning the Italian version of the shortened form of the Coping Inventory for Stressful Situations. Medicina Psicosomatica, 44, 153-162. 
Pollock, S. E (1993). Adaptation to chronic illness: A program of research for testing nursing theory. Nursing Science Quarterly, 6, 86-92.

Poser, C. M. Paty, D. W., Scheinberg, L, McDonald, W. I., Davis, F. A., Ebers, G. C., Johnson, K. P., Sibley, W. A., Silberberg, D. H, \& Tourtellotte, W. W. (1983). New diagnostic criteria for multiple sclerosis: Guidelines for research protocols. Annals of Neurology, 13, 227-231.

Scheier, M. F, \& Carver, C. S. (1985). Optimism, coping, and health: Assessment and implications of generalized outcome expectancies. Health Psychology, 4, 219-247.

Scheier, M. F, Carver, C. S., \& Bridges, M. W. (1994). Distinguishing optimism from neuroticism (and trait anxiety, self-mastery, and self-esteem): A reevaluation of the Life Orientation Test. Journal of Personality and Social Psychology, 67, 1063-1078.

Schwarzer, R. (1993). Measurement of perceived selfefficacy: Psychometric scales for crosscultural research. Berlin: Freie Universität Berlin, Institut für Psychology.

Schwarzer, R. (1994). Optimism, vulnerability, and self-beliefs as health-related cognitions: A systematic overview. Psychology and Health, 9, 161-180.

Schwarzer, R. (1999). Self-regulatory processes in the adoption and maintenance of health behaviors: The role of optimism, goals, and threats. Journal of Health Psychology, 4, 115-127.

Scott, D. L, van Riel, P. L, van der Heijde, D., \& Studnicka Benke, A. (1993). Assessing disease activity in rheumatoid arthritis. In J. S. Smolen (Ed.), The EULAR handbook of standard methods. Vienna: EULAR.

Shaul, M. P. (1995). From early twinges to mastery: The process of adjustment in living with rheumatoid arthritis. Arthritis Care and Research, 8, 290-297.

Shifren, K. (1996). Individual differences in the perception of optimism and disease severity: A study among individuals with Parkinson's disease. Journal of Behavioral Medicine, 19, 241-271.

Spinhoven, Ph., Ormel, J., Sloekers, P. P. A, Kempen, G. I. J. M., Speckens, A. E. M. \& van Hemert, A. M. (1997). A validation study of the Hospital Anxiety and Depression Scale (HADS) in different groups of Dutch subjects. Psychological Medicine, 27, 363-370.

Stuifbergen, A. K. (1995). Health-promoting behaviors and quality of life among individuals with multiple sclerosis. Scholarly Inquiry for Nursing Practice, 9, 31-50.

Taylor, S. E. (1989). Positive illusions: Creative self-deception and the bealthy mind. New York: Basic Books Harper Collins.

Taylor, S. E, \& Gollwitzer, P. M. (1995). Effects of mindset on positive illusions. Journal of Personality and Social Psychology, 69, 213-226.

Taylor, S. E., Helgeson, V. S., Reed, G. M. \& Skokan, L A. (1991). Self-generated feelings of control and adjustment to physical illness. Journal of Social Issues, 47, 91-109.

Taylor, S. E, Kemeny, M. E, Reed, G. M. \& Aspinwall, L G. (1991). Assault on the self: Positive illusions and adjustment to threatening events. In J. Strauss \& G. R. Goethals (Eds.), The self: Interdisciplinary approaches (pp. 239-254). New York: Springer.

van Lankveld, W. (1993). De reuma locus of control: De relatie tussen beheersingsorientatie ten opzichte van reumatoide artritis en keuze van copingstijlen. Dissertation.

Van der Zee, K. I. \& Sanderman, R. (1993). Het meten van de algemene gezondheidstoestand met de RAND-36: Een handleiding. Groningen, The Netherlands: Noordelijk Centrum voor Gezondheidsvraagstukken.

Wallston, K. A. (1994). Cautious optimism vs cockeyed optimism. Psychology and Health, 9, 201-203.

Wallston, K. A, Wallston, B. S., Kaplan, G. D., \& Maides, S. A. (1978). Development of the multidimensional health locus of control (MHL) scales. Health Education Monographs, 6, $160-170$.

Ware, J. E, \& Sherbourne, C. D. (1992). The MOS 36-item short form health survey (SF-36): I. Conceptual framework and item selection. Medical Care, 30, 473-483.

Weinstein, N D. (1980). Unrealistic optimism about future life events. Journal of Personality and Social Psychology, 39, 806-820. 
432 Marijda Fournier et al.

Weinstein, N. D. (1987). Unrealistic optimism about susceptibility to health problems: Conclusions from a community-wide sample. Journal of Behavioral Medicine, 10, 481-500.

Zigmond, A. S., \& Snaith, R. P. (1983). The Hospital Anxiety and Depression Scale. Acta Psychiatrica Scandinavica, 67, 361-370.

Zwanikken, C. P. (1997). Multiple Sclerose: Epidemiologie en kwaliteit van leven. Dissertation, Rijksuniversiteit Groningen.

Received 20 November 2000; revised version received I 4 May 200 I 
Copyright $\odot 2002$ EBSCO Publishing 